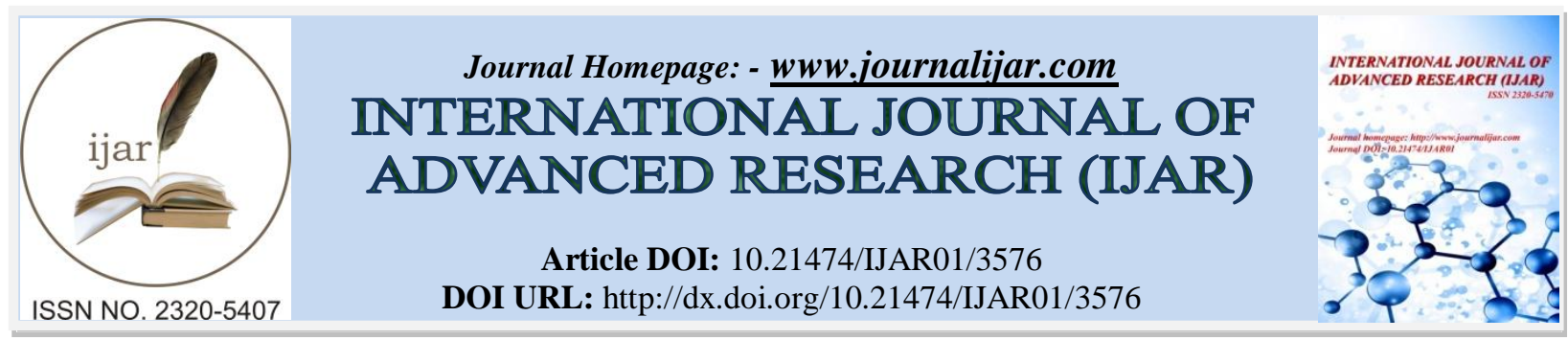

RESEARCH ARTICLE

\title{
COMPARATIVE EVALUATION OF EFFICACY OF TWO COMMERCIALLY AVAILABLE HERBAL AND ALLOPATHIC DENTIFRICE ON DENTINAL HYPERSENSITIVITY AND THEIR EFFECT ON PLAQUE AND GINGIVITIS.
}

\section{Shivanand Aspalli, Swapna Ediga, Reetika Gaddale, Nagappa Guttiganur, Anupama Desai and Mohammed Merajuddin Awesi.}

\section{Manuscript Info}

Manuscript History

Received: 04 January 2017

Final Accepted: 02 February 2017

Published: March 2017

Key words:-

Allopathic, dentinal hypersensitivity, dentifrices, gingivitis, herbal, plaque.

\section{Abstract}

Background: Dentinal hypersensitivity is a transient condition that often resolves with the natural sclerotic obturation of dentinal tubules. A potent topically applied in-office desensitizing treatment is indicated as the choice of treatment when dentinal hypersensitivity is localized to one or two teeth.

Aim: The present study aimed to evaluate and compare the clinical efficiency of two commercially available herbal and allopathic dentifrices that were used in treating dentinal hypersensitivity, additional this study evaluates their effectiveness in reducing plaque and gingivitis on both the groups.

Materials and Methods: 30 patients aged 20-60 years reporting with dentinal hypersensitivity were randomly assigned to 2 groups of 15 patients each. Plaque index scores and gingival bleeding index scores were evaluated and response to air stimuli and thermal stimuli were measured using visual analogue scale at baseline, 7 th, and $30^{\text {th }}$ day.

Statistical Analysis: Statistical analysis was carried out using Mann Whitney u test, Friedman test and Wilkoxon sign rank test.

Results: Allopathic dentifrice group showed better results in reducing dentinal hypersensitivity during 7 days assessment whereas at 30 days of evaluation herbal dentifrice group showed significant reduction in dentinal hypersensitivity. It also showed that there was no statistical significant difference between both the groups but herbal dentifrice showed better results in gingival index scores and plaque index scores.

Conclusion: Allopathic dentifrices is fast acting whereas herbal dentifrice has long term effect and has better anti plaque and anti gingivitis effect compared to allopathic dentifrice.

Copy Right, IJAR, 2017,. All rights reserved.

\section{Introduction:-}

Dentinal hypersensitivity (DH) is a characteristic pain arising from exposed dentine, typically in response to various stimuli such as thermal, evaporative, tactile, osmotic or chemical, which cannot be attributed to any other form of dental defect or pathology.

When constantly present over a long time, DH can provoke chronic discomfort and emotional distress. ${ }^{2}$ In addition; it can make dental plaque control difficult. According to hydrodynamic theory by Braennstroem and Astroem, 
enamel or cementum loss in cervical areas and the consequent opening of dentinal tubules to the oral environment, under certain stimuli, allows the movement of dentinal fluid inside the tubules, indirectly stimulating the extremities of the pulp nerves, causing pain. ${ }^{3}$ It was also found that open dentinal tubules serve as pathways for the diffusive transport of bacterial elements in the oral cavity to the pulp, which may cause a localized inflammatory pulpal response. ${ }^{4}$ Microscopic examination reveals that patent dentinal tubules are more numerous and wider in hypersensitive dentine than in non-sensitive dentine. ${ }^{5}$

Various strategies have been used in the treatment of DH which include lasers, iontophoresis, dentine sealers and soft tissue grafting. ${ }^{6}$ Toothpastes are the most widely used dentifrices for delivering over-the-counter desensitizing agents. ${ }^{7}$ Agents for topical relief of dentine hypersensitivity either block the exposed dentine tubules or have a direct desensitizing effect on the pulpal nerve fibres. ${ }^{8,9}$ The use of potassium nitrate as an effective desensitizing agent dates backs to the testimonial report of Hodosh in $1974 .{ }^{10}$ Since then, many pastes containing potassium chloride or potassium citrate have been made available. ${ }^{11}$

Recently there has been a growing interest in natural products, and herbal based toothpastes have been found as effective as the conventionally formulated dentifrice in the control of plaque and gingivitis. ${ }^{12}$

This was the first study which was conducted to assess and compare the efficacy of a commercially available novel herbal dentifrice containing potassium nitrate and spinacia oleracia to an allopathic dentifrice which contains potassium nitrate on $\mathrm{DH}$ and also to evaluate anti plaque and anti gingivitis effects of both the tooth pastes over a period of 4 weeks.

\section{Methodology:-}

A total of 30 patients were selected from department of periodontics and oral implantology,A.M.E'S Dental college and hospital,Raichur,Karnataka, India with dentinal hypersensitiviy. The individuals selected at baseline had a history of DH caused by gingival recession, cervical erosion, and attrition. Subjects age ranging from 20-60 years were required to have 20 natural permanent teeth and at least two teeth with a VAS score of $\geq 4$. Allergic to ingredients, teeth with occlusal overload, teeth with caries, defective restorations, and chipped teeth were excluded.

After obtaining patient informed consent, oral prophylaxis with oral hygiene instructions was given. Randomisation was done to allocate patients in two groups, group A-Herbal dentifrice -HiOra K, (The Himalaya Drug Company Research and Development, Makali, Bangalore) and group B-Allopathic dentifrice-Sensodent K (Warren pharma). Each gram of Hi Ora K dentifrice contained $2.5 \mathrm{mg}$ Cinnamomum zeylanicum, $2.5 \mathrm{mg}$ Syzygium aromaticum, 10.0 $\mathrm{mg}$ Spinacia oleracea, $6.0 \mathrm{mg}$ Triphala, $4.0 \mathrm{mg}$ Trikatu and $30.0 \mathrm{mg}$ Suryakshara (Potassium nitrate) and $10.0 \mathrm{mg}$ Yashada bhasma (zinc oxide), sodium benzoate, calcium carbonate with sorbitol, glycerine and xanthan gum. Each gram of Sensodent-K contains $5 \%$ of potassium nitrate. Plaque index and gingival index were recorded and hypersensitivity response to air stimuli using air jet from triple syringe \& thermal stimuli using cold water was evaluated on the VAS, at baseline. After recording sensitivity scores and plaque index and gingival index scores at baseline, subjects were randomly given dentifrice and advised to use it with a soft bristle toothbrush twice daily for 3 weeks. Patients were recalled after 1 week and 4 weeks for clinical assessment.

\section{Statistical analysis:-}

Statistical analysis was carried out using Mann Whitney $\mathrm{u}$ test and Friedman test to compare two individual independent groups at baseline, 1 week and 4 weeks. Wilkoxon sign rank test was used as post hoc test for intergroup comparison. 


\section{Results:-}

Table I- Percentage change in mean sensitivity scores for two groups at all time points for both measures of plaque scores, gingivitis scores and sensitivity score

\begin{tabular}{|l|l|l|l|l|}
\hline \multirow{2}{*}{ Groups } & Clinical assessment & \multicolumn{3}{l|}{ Change in mean sensitivity score (\%) } \\
\cline { 2 - 5 } & & Baseline to 1week & Baseline to 4 week & 1 to 4weeks \\
\hline \multirow{4}{*}{ Group-A } & Plaque scores & $-88.63 \pm 42.9$ & $-139.26 \pm 69.3$ & $-51.9 \pm 65.5$ \\
\cline { 2 - 5 } & Gingival scores & $-97.93 \pm 41.9$ & $-174.33 \pm 58.56$ & $-76.4 \pm 44.3$ \\
\cline { 2 - 5 } & Thermal stimulus & $-100.2 \pm 49.8$ & $-267.2 \pm 82.4$ & $-167 \pm 66.18$ \\
\cline { 2 - 5 } & Air stimulus & $-111.2 \pm 32.4$ & $-255.8 \pm 59.2$ & $-144.6 \pm 54.8$ \\
\hline \multirow{5}{*}{ Group-B } & Plaque scores & $-78.16 \pm 34.02$ & $-130.1 \pm 54.3$ & $-50.63 \pm 78.5$ \\
\cline { 2 - 5 } & Gingival scores & $-83.26 \pm 51.05$ & $-147.73 \pm 56.6$ & $-88.73 \pm 42.03$ \\
\cline { 2 - 5 } & Thermal stimulus & $-115.53 \pm 46.43$ & $-231.81 \pm 56.76$ & $-116.26 \pm 40$ \\
\cline { 2 - 5 } & Air stimulus & $-118.2 \pm 55.70$ & $-229.13 \pm 65.54$ & $-110.9 \pm 34.2$ \\
\hline
\end{tabular}

Table II:- Comparison of two groups of percentage change in plaque, gingivitis, air and thermal sensitivity scores.

\begin{tabular}{|l|l|l|l|l|}
\hline & & Baseline to 1 week & Baseline to 4 weeks & 1week to 4 weeks \\
\hline \multirow{3}{*}{ Plaque scores } & $\mathrm{t}$ value & 0.740 & 0.402 & -0.050 \\
\cline { 2 - 5 } & $\mathrm{P}$ value & 0.466 & 0.691 & 0.960 \\
\hline \multirow{3}{*}{ Gingival scores } & $\mathrm{t}$ value & -0.86 & -1.264 & 0.498 \\
\cline { 2 - 5 } & $\mathrm{P}$ value & 0.397 & 0.217 & 0.441 \\
\hline \multirow{2}{*}{ Air Stimulus } & $\mathrm{t}$ value & 0.871 & -1.369 & -2.001 \\
\cline { 2 - 5 } & $\mathrm{P}$ value & 0.391 & 0.182 & $\mathbf{0 . 0 1 7}$ \\
\hline & $\mathrm{t}$ value & 0.421 & -1.169 & -2.016 \\
\cline { 2 - 5 } & P value & 0.677 & 0.252 & $\mathbf{0 . 0 5}^{*}$ \\
\hline
\end{tabular}

*Statistically significant

\section{Discussion:-}

HiOra K dentifrice contains Cinnamomum zeylanicum that has been found to have bactericidal properties and is found to be equally effective against both Gram-positive and Gram-negative organisms. Cinnamaldehyde, the predominant active compound in cinnamon oil, has been found to be a natural antioxidant. ${ }^{13}$ Extract of Syzygium aromaticum (clove) has been found to exhibit growth-inhibitory activity against Gram-negative anaerobic periodontal oral pathogens, including Porphyromonas gingivalis and Prevotella intermedia. ${ }^{14}$ Triphala has been found to have similar effects on dental plaque and gingival inflammation compared to chlorhexidine. ${ }^{15}$ Trikatu has anti-inflammatory properties. ${ }^{16}$ Yashada bhasma contains zinc and has been formulated into oral health products to control plaque, reduce malodor and inhibit calculus formation. ${ }^{17,18}$

In the present study dentinal hypersensitivity was reduced in allopathic dentifrice group during 7 days assessment whereas after 30 days herbal dentifrice group showed significant reduction in dentinal hypersensitivity. This means that desensitizing affect was maintained even 7 days after discontinuing the product in herbal dentifrice group, this might be due to the component Spinacia oleracea present in HiOra K group. Spinacia oleracea may have a possible mechanism of having a synergistic effect along with potassium nitrate in reducing DH by its dentinal tubule obliterating property ,as Spinacia oleracea was absent in the group B there was not statistical difference at 30 days. It has been found that potassium nitrate does not diminish dentine hydraulic conductivity, or promote obstruction of dentinal tubules by the deposition of crystals. According to Wilchgers ${ }^{19}$ and Ermert ${ }^{20}$ potassium nitrate has an effective desensitizing action. The increase in the concentration of extracellular potassium around the nerve fibers causes their depolarization, avoids repolarization and blocks the axonic action and passage of nerve stimulus, thus inactivating the action potential. ${ }^{19,}{ }^{20}$. Hence it was shown that group B which contains $5 \%$ of potassium nitrate showed rapid relief in hypersensitivity during 7th day of assessment. In another study which compared HiOra $\mathrm{K}$ with that of placebo, Sensitivity scores for controlled air stimulus and cold water were recorded at baseline, 6 weeks and 12 weeks and concluded that test group was found to be significantly better compared to the placebo group at the end of 6 and 12 weeks in reduction of dentinal hypersensitivity. ${ }^{21}$ 
As per our knowledge this is the first study which also compared the effectiveness of desensitizing agents on plaque and gingivitis and it has be shown that there was no statistical significant difference between both the groups, but HiOra K showed better results in gingival index scores and plaque index scores which might be due to the presence of triphala which has effect on dental plaque and gingival inflammation.

\section{Conclusion:-}

Allopathic dentifrices had shown significant reduction in dentinal hypersensitivity at 7 days but herbal dentifrice had shown better results at 1 month follow up, which may be due to presence of spinacia oleracea. Effect of antiplaque and gingivitis was also shown better results in herbal dentifrice group. Therefore according to our study, allopathic dentifrices is fast acting whereas herbal dentifrice has long term effect and has better antiplaque and antigingivitis effect compared to allopathic dentifrice.

\section{Reference:-}

1. Dowell P, Addy M. Dentine hypersensitivity - a review, aetiology, symptoms and theories of pain production. J Clin Periodontol 1983;10:341-350.

2. Narhi M, Yamamoto H, Ngassapa D, Hirvonen T. The neurophysiological basics and the role of inflammatory reactions in dentine hypersensitivity. Arch Oral Biol 1994;39:23S-30S.

3. Braennstroem M, Astroem A. A study on the mechanism of pain elicited from the dentin. J Dent Res 1964;43:619-625.

4. Bergenholtz G, Lindhe J. Effect of soluble plaque factors on inflammatory reactions in the dental pulp. Scand J Dent Res 1975;83:153-158.

5. Absi EG, Addy M, Adams D. Dentine hypersensitivity: a study of the patency of dentinal tubules in sensitive and nonsensitive cervical dentine. J Clin Periodontol 1987;14:280-284.

6. Bartold PM. Dentinal hypersensitivity. Aust Dent J 2006;51:212-218.

7. Orchardson R, Gillam DG. Managing dentin hypersensitivity. J Am Dent Assoc 2006;137:990-998; quiz 10281029.

8. Kim S. Hypersensitive teeth: desensitization of pulpal sensory nerves. J Endod 1986;12:482-485.

9. Kleinberg I. Dentinal hypersensitivity. Part II: Treatment of sensitive dentin. Compend Contin Educ Dent 1986;7:280.

10. Hodosh M. A superior desensitizer-potassium nitrate. J Am Dent Assoc 1974;88:831-832.

11. Orchardson R, Gillam DG. The efficacy of potassium salts as agents for treating dentin hypersensitivity. J Orofac Pain 2000;14:9-19.

12. Mullally BH, James JA, Coulter WA, Linden GJ. The efficacy of a herbal-based toothpaste on the control of plaque and gingivitis. J Clin Periodontol 1995;22:686-689.

13. Prabuseenivasan S, Jayakumar M, Ignacimuthu S. In vitro antibacterial activity of some plant essential oils. BMC Complement Altern Med 2006;6:39.

14. Cai L, Wu CD. Compounds from Syzygium aromaticum possessing growth inhibitory activity against oral pathogens. J Nat Prod 1996;59:987-990.

15. Bajaj N, Tandon S. The effect of Triphala and Chlorhexidine mouthwash on dental plaque, gingival inflammation, and microbial growth. Int J Ayurveda Res 2011;2:29-36.

16. Chanda D, Shanker K, Pal A, et al. Safety evaluation of Trikatu, a generic Ayurvedic medicine in Charles Foster rats. J Toxicol Sci 2009;34:99-108.

17. Prajapati PK, Sarkar PK, Nayak SV, Joshi RD, Ravishankar B. Safety and toxicity profile of some metallic preparations of ayurveda. Anc Sci Life 2006;25:57-63.

18. Lynch RJ. Zinc in the mouth, its interactions with dental enamel and possible effects on caries; a review of the literature. Int Dent J 2011;61:46-54.

19. Peacock JM, Orchardson R. Effects of potassium ions on action potential conduction in A- and C-fibers of rat spinal nerves. J Dent Res 1995;74:634-641.

20. Wichgers TG, Emert RL. Dentin hypersensitivity. Oral Health 1997;87:51-53.

21. M Kumari, SB Naik, NS Rao,SS Martande, AR Pradeep. Clinical efficacy of a herbal dentifrice on dentinal hypersensitivity: a randomized controlled clinical trial. Australian Dental Journal 2013; 58: 483-49 